\title{
EFFECT OF METEOROLOGY AND SOIL FERTILITY ON DIRECT-SEEDED RICE (ORYZA SATIVA L.) PERFORMANCE IN CENTRAL CHINA
}

\author{
JiANG, S. C. ${ }^{1,2}-$ WANG, J. M. ${ }^{1,2}-$ LUO, H. W. ${ }^{3}-$ XIE, Y. M. ${ }^{4}-$ FENG, D. H. ${ }^{1}-$ ZHOU, L. ${ }^{4}-$ \\ SHI, L. ${ }^{1}-$ CHEN, H. ${ }^{4}-$ XU, Y. Y. ${ }^{1}-$ WANG, M. ${ }^{1}-$ XING, D. Y. ${ }^{1,2^{*}}$ \\ ${ }^{1}$ College of Agriculture, Yangtze University, 434025 Jingzhou, PR China \\ ${ }^{2}$ Hubei Cooperative Innovation Center for Major Food Crops, 434025 Jingzhou, PR China \\ ${ }^{3}$ Department of Crop Science and Technology, College of Agriculture, South China Agricultural \\ University, Guangzhou 510642, PR China \\ ${ }^{4}$ National Quality Supervision and Testing Center for Selenium Products \\ 445000 Enshi, PR China \\ ${ }^{\#}$ These authors have contributed equally to this work \\ "Corresponding author \\ e-mail: xingdy_2006@126.com \\ (Received $9^{\text {th }}$ May 2019; accepted $16^{\text {th }}$ Jul 2019)
}

\begin{abstract}
The aim of this study was to study the effect of meteorology and soil fertility on direct-seeded rice growing period and yield formation. A two year field experiment was conducted with six rice varieties (Fengliangyou 2 (FYL-2), Fengliangyouxiang-1 (FLYX-1), Liangyou 168 (LY-168), Guofeng-1 (GF-1), Quanyou-801 (QY-801) and Japonica Rice-107 (WD-107)) in Central China during 2017 and 2018. Two soil fertilities (high fertility and low fertility) were texted in present study. The result showed that the difference in temperature and sunshine hours during the growth periods between 2017 and 2018 induced the difference in growing period and grain yield. On the other hand, compared to low soil fertility, high soil fertility significantly increased grain yield of direct seeded rice by promoting panicle number and grain number. The highest yield was recorded in $Q Y-801$ in both years and both soil fertilities, Quanyou-801 might be the most suitable variety for direct-seeded rice planting in Central China.
\end{abstract}

Keywords: soil condition, yield, yield component, path analysis, fertilization method

\section{Introduction}

As the main crop in China, rice is the first in terms of planting area and yield, thus, ensuring a stable increase in rice production is the basic condition of Chinese food security (Chen et al., 2016). As far as seedling raising methods are concerned, rice cultivation can be divided into direct seeding cultivation and transplanting cultivation. Compared with traditionally transplanted rice production system, the technology of direct-seed rice has the advantages of labor-saving, rice seedling field-saving, short growth period, high yield and high efficiency, and it is more suitable for large-scale cultivation and plays an important role in the process of agricultural mechanization in China (Pan et al., 2017). Direct-seeded rice is characterized by continuous growth, low tiller node position, rapid growth process, few leaves, rapid population formation and large scale (Hu et al., 2019). Its photosynthetic capacity is high in the early stage, low in the middle and late stages, and its yield formation is characterized by more panicles, 
smaller panicle type, and lower grain filling and setting level (Wang et al., 2018; Du et al., 2019). Normally, the yield of direct-seeded rice is not only affected by its own genetic conditions and acquired crop management, but also influenced by the environment of paddy field.

Meteorology and soil are the main influencing factors for rice growth and development. Some previous studies showed the influence of climate on rice performance. For example, the study of Mo (2017) found that temperature fluctuations at critical growth stages of rice may cause crop yield loss, shifts in crop growth periods as well as in sowing and harvesting times. Kong (2017) demonstrated high temperature during the grain filling stage not only reduced the fragrant rice yield, but also affected grain quality. Rao (1988) even obtained the correlations between weather parameters and the biomass of rice. As far as soil condition is concerned, there are regional differences in soil conditions in China and the spatial variation is small (Sun et al., 2008). Tang (2009) compares the influence of soil fertility on three major food crops and finds the soil contribution rate to rice production and basic yield. Seyfferth (2014) investigated the effect of arsenic concentrations in soil on major rice-growing regions in Cambodia. Furthermore, there is a significant difference in fertilizer contribution rate, basic soil contribution rate and yield when the same rice genotype grows under different soil conditions (Zou et al., 2015). However, there was no much study about environmental effect on direct-seeded rice performance reported.

Thus, present study was conducted in Hubei province (major rice producing province in Central China) in order to study the effect of different soil fertility and meteorology on direct-seeded rice performance in different rice genotypes.

\section{Materials and methods}

\section{Experimental design and crop management}

Two years experiment was conducted in Taihu Farm, Jingzhou City during 2017 and 2018 (longitude $30^{\circ} 34^{\prime} 57$, dimension $112^{\circ} 04^{\prime} 78$ ). Six rice varieties were used in present study: Fengliangyou 2 (FYL-2), Fengliangyouxiang-1 (FLYX-1), Liangyou 168 (LY168), Guofeng-1 (GF-1), Quanyou-801 (QY-801) and Japonica Rice-107 (WD-107), which are provided by Jingzhou Fulongxing Seed Industry Co., Ltd. The rice seeds were sowed into experiment fields on June 20, 2017 and 2018. Before sowing, the seeds were soaked in water for $24 \mathrm{~h}$, germinated in manual climatic boxes for another $10 \mathrm{~h}\left(33^{\circ} \mathrm{C}\right)$, then shade-dried. Pre-germinated seeds of six rice genotypes were hill-seeded with direct-seeded machine into two different fertility soils at a space of $25 \times 15 \mathrm{~cm}$ while each hill was planted with 3-5 seeds. The soil fertilities were shown in Table 1.

The treatments were arranged in randomized complete block design (RCBD) in triplicate with net plot size of $12 \mathrm{~m}^{2}$. The temperature and sunshine hours during the experiment were shown in Figure 1.

Nitrogen fertilizer was applied to the field in the form of urea 1 day before sowing, rice 3 leaf stage and rice booting stage according to the ratio of 6:2:2. The total amount was $\mathrm{N} 134.60 \mathrm{~kg} \mathrm{hm}^{-2}$, and the phosphate fertilizer passed the superphosphate one day before sowing. The form is applied to the field at one time, the total dosage is $\mathrm{P}_{2} \mathrm{O}_{5}$ $79 \mathrm{~kg} \mathrm{hm}^{-2}$, and the potassium fertilizer is applied to the field in the form of potassium chloride in the ratio of 7:3,1 day before sowing and rice booting stage, the total dosage is $\mathrm{K}_{2} \mathrm{O} 97 \mathrm{~kg} \mathrm{hm}^{-2}$. Fertilization management for two years is exactly the same. The 
field management refers to the local rice high-yield management requirements, timely drying the fields, and doing pest control and weed control.

Table 1. The fertility from two soil conditions

\begin{tabular}{l|c|c|c|c|c|c|c|c}
\hline & $\begin{array}{c}\text { Total } \\
\text { nitrogen } \\
\left(\mathrm{g} \mathrm{kg}^{-1}\right)\end{array}$ & $\begin{array}{c}\text { Total } \\
\text { phosphorus } \\
\left(\mathrm{g} \mathrm{kg}^{-1}\right)\end{array}$ & $\begin{array}{c}\text { Total } \\
\text { potassium } \\
\left(\mathrm{g} \mathrm{kg}^{-1}\right)\end{array}$ & $\begin{array}{c}\text { Available } \\
\text { nitrogen } \\
\left(\mathrm{mg} \mathrm{kg}^{-1}\right)\end{array}$ & $\begin{array}{c}\text { Available } \\
\text { phosphorus } \\
\left(\mathrm{mg} \mathrm{kg}^{-1}\right)\end{array}$ & $\begin{array}{c}\text { Available } \\
\text { potassium } \\
\left(\mathrm{mg} \mathrm{kg}^{-1}\right)\end{array}$ & $\begin{array}{c}\text { Organic } \\
\text { matter } \\
\left(\mathrm{g} \mathrm{kg}^{-1}\right)\end{array}$ & PH \\
\hline Low & 1.99 & 0.99 & 13.55 & 87.21 & 38.43 & 129.23 & 17.80 & 5.56 \\
High & 2.78 & 1.08 & 14.69 & 151.63 & 28.41 & 209.10 & 25.86 & 5.45 \\
\hline
\end{tabular}
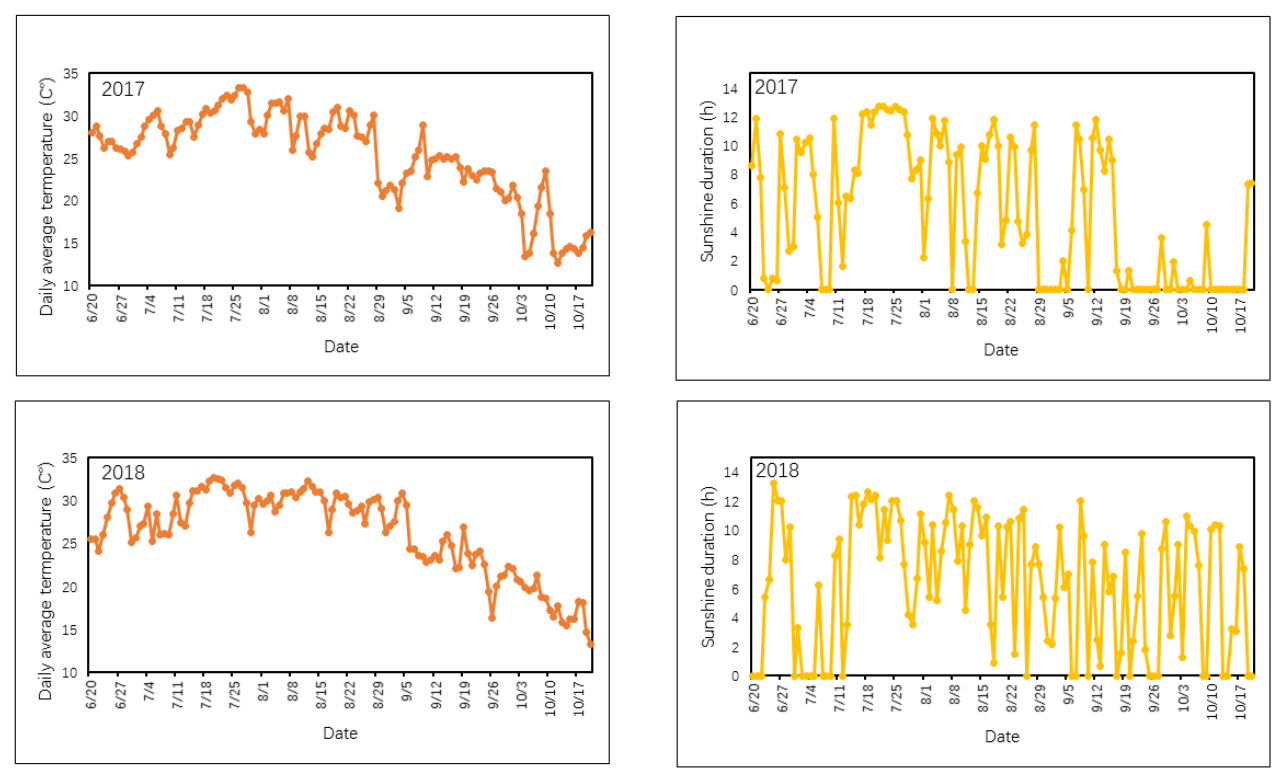

Figure 1. The air temperature and sunshine duration during the experiment

Water managements were followed as adopted by local farmers. No standing water was kept in the field from sowing to the three-leaf stage of rice, subsequently, the field was reflooded to about $3 \mathrm{~cm}$ water depth until the end of the tillering stage. Then, water was drained for about 7 days to control the production of non-productive tillers. At the following stages, water layer at soil surface was maintenance at $5 \mathrm{~cm}$ until grain filling stage. All other agronomic practices i.e., pest and diseases management, and weed control were the same in all treatments by following the guidelines and standards recommended by the province.

\section{Determination of rice yield and growth period}

After the direct-seeding, the three-leaf stage, booting stage, heading stage, flowering stage and maturity stage of rice were recorded. At maturity, the rice grains were harvested from ten-unit sampling area $\left(10.00 \mathrm{~m}^{2}\right)$ in each plot and then threshed by machine. The harvested grains were sundried by a small thresher (150A, Maizhe, Hangzhou, China) and dried (101-0A, Keheng, Shanghai, China), then and weighed to estimate grain yield. Thirty hills of rice from different locations in each plot were sampled for estimating the average effective panicles number per hill. Six hills representative plants were taken for estimation of the yield related traits. 


\section{Statistical analysis}

Data were analyzed by using statistical software by ANOVA (SPSS, 21.0) while differences amongst means were separated by using least significant difference (LSD) test at 5\% probability level. Graphical representation was conducted via Sigma Plot 14.0 (Systat Software Inc., California, USA).

\section{Results}

\section{Growth period}

The growth process of rice was shown in Table 2. It could be observed the growth period of all varieties is within 130 days, of which the growth period of 2018 is in the range of 113-125 days, and the whole growth period of FLY-2 and WD-107 under low soil fertility was 1 day longer than high fertility. However, there was no remarkable difference between two soil fertility conditions in other rice varieties.

Table 2. Fertility progress of various varieties in 2017 and 2018

\begin{tabular}{|c|c|c|c|c|c|c|c|c|c|c|c|}
\hline \multirow{2}{*}{\multicolumn{2}{|c|}{ Variety }} & \multicolumn{5}{|c|}{2017} & \multicolumn{5}{|c|}{2018} \\
\hline & & SS-TI & TI-PI & PI-HD & HD-MA & AA-MA & SS-TIa & TI-PI & PI-HD & HD-MA & AA-MA \\
\hline \multirow{6}{*}{ High } & $G F-1$ & 20 & 36 & 20 & 39 & 115 & 20 & 35 & 19 & 39 & 113 \\
\hline & $F L Y-2$ & 25 & 42 & 22 & 40 & 129 & 25 & 40 & 20 & 39 & 124 \\
\hline & $W D-107$ & 22 & 40 & 22 & 40 & 124 & 22 & 38 & 21 & 40 & 121 \\
\hline & $L Y-168$ & 20 & 37 & 20 & 39 & 116 & 20 & 36 & 19 & 39 & 114 \\
\hline & $F L Y X-1$ & 23 & 37 & 20 & 39 & 119 & 23 & 36 & 19 & 39 & 117 \\
\hline & $Q Y-801$ & 24 & 39 & 22 & 40 & 125 & 24 & 38 & 21 & 40 & 123 \\
\hline \multirow{6}{*}{ Low } & $G F-1$ & 20 & 37 & 20 & 39 & 116 & 20 & 35 & 19 & 39 & 113 \\
\hline & $F L Y-2$ & 25 & 44 & 21 & 40 & 130 & 25 & 41 & 20 & 39 & 125 \\
\hline & $W D-107$ & 22 & 41 & 22 & 40 & 125 & 22 & 39 & 21 & 40 & 122 \\
\hline & $L Y-168$ & 20 & 37 & 20 & 39 & 116 & 20 & 36 & 19 & 39 & 114 \\
\hline & $F L Y X-1$ & 23 & 37 & 20 & 39 & 119 & 23 & 36 & 19 & 39 & 117 \\
\hline & $Q Y-801$ & 24 & 39 & 22 & 40 & 125 & 24 & 38 & 21 & 40 & 123 \\
\hline
\end{tabular}

Three-leaf stage (SS-TI): time from seeding to trifoliate; booting stage (SS-PI): time from tillering to booting stage; heading period (PI-HD): time from the end of the booting to the heading; maturity: time from the head to maturity; total growth period: the time from the start of sowing to maturity. The same below

The growth period in 2017 ranged between 115-130 days. The entire growth periods of $G F-1, F L Y-2, W D-107$ under low soil fertility were 1 more day than the high fertility, whilst there was no significant difference observed between different soil fertility among the other varieties. Moreover, the growth period in 2017 is 2 to 5 days older than 2018. The growth period of FLY-2 in 2017 is 5 days longer than 2018 while other varieties were 2 to 3 days longer.

\section{Grain yield and its related trails}

As shown in Table 3, the yield of direct-seeded rice varies among years, soil fertilities and genotype. Compared to low soil fertility, high soil fertility remarkably increased the rice yield by $6.52 \%-12.22 \%$. The increment could be explained by the improvement in the panicle number. Compared with low soil fertility, the number of 
effective panicles increased by $0.56 \%-8.51 \%$ due to high soil fertility. Moreover, higher grain number per panicles were recorded in high soil fertility than low soil fertility for $L Y-168$, FLYX-1, QY-801 in both 2017 and 2018. On the other hand, compared to 2017, lower seed-setting rates were recorded in 2018 for $G F-1, L Y-168$, FLYX-1.

Table 3. Effect of different soil fertility on rice yield and related trails

\begin{tabular}{|c|c|c|c|c|c|c|c|}
\hline Year & Soil fertility & Variety & $\begin{array}{l}\text { Panicle number } \\
\left(10^{4} \mathrm{ha}^{-1}\right)\end{array}$ & $\begin{array}{c}\text { Grain } \\
\text { number per } \\
\text { panicle }\end{array}$ & $\begin{array}{c}\text { Seed-setting } \\
\text { rate } \\
(\%) \\
\end{array}$ & $\begin{array}{c}1000 \text {-grain weight } \\
(\mathrm{g})\end{array}$ & $\begin{array}{c}\text { Grain yield } \\
\left(\mathrm{kg} \mathrm{ha}^{-1}\right)\end{array}$ \\
\hline \multirow{14}{*}{2017} & \multirow{6}{*}{ Low } & GF-1 & $201.5 b$ & $182.6 \mathrm{a}$ & $86.4 \mathrm{a}$ & $27.7 \mathrm{bc}$ & $7837.0 \mathrm{a}$ \\
\hline & & FLY-2 & 205.4ab & $187.0 \mathrm{a}$ & $83.1 \mathrm{ab}$ & $27.3 \mathrm{c}$ & $7589.4 b$ \\
\hline & & WD-107 & $217.3 \mathrm{a}$ & $181.3 \mathrm{a}$ & $80.0 \mathrm{~b}$ & $28.1 b c$ & $7388.6 d$ \\
\hline & & LY-168 & $207.4 \mathrm{ab}$ & $173.9 \mathrm{a}$ & $80.1 \mathrm{~b}$ & $29.6 a$ & $7918.2 \mathrm{a}$ \\
\hline & & FLYX-1 & $210.1 \mathrm{ab}$ & $173.8 \mathrm{a}$ & $81.90 \mathrm{~b}$ & $27.4 \mathrm{c}$ & $7496.9 \mathrm{c}$ \\
\hline & & QY-801 & $199.7 \mathrm{ab}$ & $203.9 \mathrm{a}$ & 83.0ab & $28.4 b$ & $7940.4 a$ \\
\hline & & Mean & 207.0 & 183.7 & 82.4 & 28.1 & 7695 \\
\hline & \multirow{6}{*}{ High } & GF-1 & $214.3 \mathrm{~b}$ & $182.9 \mathrm{~b}$ & $84.4 \mathrm{a}$ & $28.5 \mathrm{ab}$ & $8584.0 \mathrm{a}$ \\
\hline & & FLY-2 & $225.6 \mathrm{ab}$ & $184.9 \mathrm{~b}$ & $82.8 \mathrm{ab}$ & $28.4 \mathrm{ab}$ & $8468.3 \mathrm{ab}$ \\
\hline & & WD-107 & $232.8 \mathrm{a}$ & $187.1 \mathrm{~b}$ & $81.2 \mathrm{ab}$ & $28.0 \mathrm{~b}$ & $8404.2 \mathrm{~b}$ \\
\hline & & LY-168 & $220.5 \mathrm{ab}$ & $198.2 \mathrm{ab}$ & $79.9 b$ & $28.8 \mathrm{a}$ & $8472.0 \mathrm{ab}$ \\
\hline & & FLYX-1 & $213.4 b$ & $198.8 \mathrm{ab}$ & $84.9 \mathrm{a}$ & $27.8 \mathrm{~b}$ & $8413.6 \mathrm{ab}$ \\
\hline & & QY-801 & $207.0 \mathrm{~b}$ & $233.0 \mathrm{a}$ & $81.7 \mathrm{ab}$ & $28.9 \mathrm{a}$ & $8553.4 \mathrm{a}$ \\
\hline & & Mean & 219.0 & 197.5 & 82.5 & 28.4 & 8399.2 \\
\hline \multirow{14}{*}{2018} & \multirow{6}{*}{ Low } & GF-1 & $208.6 \mathrm{a}$ & $182.4 \mathrm{a}$ & $80.9 b c$ & $27.4 \mathrm{c}$ & $7567.1 \mathrm{~b}$ \\
\hline & & FLY-2 & $202.8 \mathrm{a}$ & $174.2 \mathrm{ab}$ & $84.0 \mathrm{a}$ & $28.5 b$ & $7638.5 b$ \\
\hline & & WD-107 & $222.3 \mathrm{a}$ & $165.0 \mathrm{~b}$ & $79.9 \mathrm{~cd}$ & $27.6 c$ & $7466.6 c$ \\
\hline & & LY-168 & $215.4 \mathrm{a}$ & $175.6 \mathrm{ab}$ & $75.5 \mathrm{~d}$ & $28.3 b c$ & $7399.6 \mathrm{~cd}$ \\
\hline & & FLYX-1 & $211.7 \mathrm{a}$ & $173.4 \mathrm{ab}$ & $78.9 \mathrm{~cd}$ & $28.5 b$ & 7363.6d \\
\hline & & QY-801 & $205.5 \mathrm{a}$ & $176.8 \mathrm{ab}$ & $84.0 \mathrm{a}$ & $30.7 \mathrm{a}$ & $8011.4 \mathrm{a}$ \\
\hline & & Mean & 211 & 174.6 & 80.5 & 28.5 & 7574.5 \\
\hline & \multirow{6}{*}{ High } & GF-1 & $220.6 a$ & $183.9 \mathrm{ab}$ & $82.8 b c$ & $28.2 b$ & $8409.9 b$ \\
\hline & & FLY-2 & $219.7 \mathrm{a}$ & $173.8 \mathrm{~b}$ & $83.4 \mathrm{ab}$ & $29.7 \mathrm{a}$ & $8505.4 \mathrm{a}$ \\
\hline & & WD-107 & $229.9 a$ & $166.4 \mathrm{c}$ & $80.3 b c$ & $28.4 b$ & $8425.8 b$ \\
\hline & & LY-168 & $228.5 \mathrm{a}$ & $182.8 \mathrm{~b}$ & $78.0 \mathrm{c}$ & $27.8 \mathrm{~b}$ & $8114.5 d$ \\
\hline & & FLYX-1 & $212.9 \mathrm{a}$ & $178.7 \mathrm{~b}$ & $79.3 \mathrm{c}$ & $28.2 b$ & $8263.1 \mathrm{c}$ \\
\hline & & QY-801 & $212.6 \mathrm{a}$ & $199.2 \mathrm{a}$ & $82.2 \mathrm{a}$ & $30.8 \mathrm{a}$ & $8534.2 \mathrm{a}$ \\
\hline & & Mean & 224.9 & 180.8 & 81.0 & 28.9 & 8375.5 \\
\hline \multirow{7}{*}{$\begin{array}{c}\text { Analysis of } \\
\text { Variance }\end{array}$} & \multicolumn{2}{|c|}{ Soil fertility $(\mathrm{F})$} & $* *$ & $*$ & $*$ & $* *$ & $* *$ \\
\hline & \multicolumn{2}{|c|}{ Varieties (V) } & $* *$ & $* *$ & $* *$ & $* *$ & $* *$ \\
\hline & \multicolumn{2}{|c|}{ Year (Y) } & ns & $*$ & $* *$ & $*$ & $* *$ \\
\hline & \multicolumn{2}{|c|}{$\mathrm{F} \times \mathrm{V}$} & $* *$ & $*$ & ns & ns & $*$ \\
\hline & \multicolumn{2}{|c|}{$\mathrm{F} \times \mathrm{Y}$} & $\mathrm{ns}$ & $\mathrm{ns}$ & $\mathrm{ns}$ & $\mathrm{ns}$ & $\mathrm{ns}$ \\
\hline & \multicolumn{2}{|c|}{$\mathrm{V} \times \mathrm{Y}$} & $\mathrm{ns}$ & ns & $\mathrm{ns}$ & ns & ns \\
\hline & \multicolumn{2}{|c|}{$\mathrm{F} \times \mathrm{V} \times \mathrm{Y}$} & ns & ns & ns & ns & ns \\
\hline
\end{tabular}

The same letter indicates that the variety is not significantly different under the LSD (0.05) method at the same place and year, and the same letter is reversed. The total line represents a comparison of differences between different fertility. The same below

\section{Correlation analysis and path analysis}

The correlation analysis between yield structure and yield was shown in Table 4. For low soil fertility, the effective panicle per had a negative significant correlation with both seed setting rate and grain weight whilst there exited a significant positive correlation between seed setting rate and grain yield. For high soil fertility, there exited a significant negative correlation between grain number and effective panicle whilst the 
grain yield had a significant positive correlation with both seed setting rate and 1000grain yield.

The path analysis of yield structure and yield was shown in Table 5. The order of the effects of the two fertility on yield is 1000-grain weight $>$ seed setting rate $>$ effective panicle per unit area $>$ number per panicle. The effective panicle number per unit area under low fertility had a high negative impact on yield through yield (-0.0676), with a high positive impact on yield through 1000-grain weight (0.0452), and the effective panicle number per unit area under high fertility through seed set rate $(-0.0141)$ and 1000 -grain weight $(-0.0380)$ had a high negative impact on yield. The seed setting rate under two fertility conditions had a high positive impact on yield through 1000-grain weight.

Table 4. Correlation between yield component factors and yield

\begin{tabular}{c|ccccc|ccccc}
\hline & \multicolumn{3}{|c|}{ Low } & \multicolumn{5}{c}{ High } \\
\cline { 2 - 11 } & $\mathrm{X}_{1}$ & $\mathrm{X}_{2}$ & $\mathrm{X}_{3}$ & $\mathrm{X}_{4}$ & $\mathrm{Y}$ & $\mathrm{X}_{1}$ & $\mathrm{X}_{2}$ & $\mathrm{X}_{3}$ & $\mathrm{X}_{4}$ & $\mathrm{Y}$ \\
\hline $\mathrm{X}_{1}$ & 1 & & & & & 1 & & & \\
$\mathrm{X}_{2}$ & -0.029 & 1 & & & & $-0.610^{*}$ & 1 & & \\
$\mathrm{X}_{3}$ & $-0.731^{* *}$ & 0.3491 & 1 & & & -0.390 & 0.123 & 1 & \\
$\mathrm{X}_{4}$ & -0.209 & -0.100 & 0.043 & 1 & & -0.384 & 0.192 & 0.259 & 1 & \\
$\mathrm{Y}$ & $-0.726^{* *}$ & 0.413 & $0.631^{*}$ & $0.593 *$ & 1 & -0.416 & 0.343 & $0.707 * *$ & $0.557^{* *}$ & 1 \\
\hline
\end{tabular}

$\mathrm{X} 1$ : effective panicle per unit area (plant/hm2); X2: number of grains per panicle; X3: seed setting rate; X4: 1000-grain weight; Y: grain yield $\left(\mathrm{kg} \mathrm{ha}^{-1}\right)$ the same.

* represents a significant correlation at the 0.05 level, and ** represents a very significant correlation at the 0.01 level

Table 5. Path analysis of yield components and yield

\begin{tabular}{c|c|c|c|c|c|c|c}
\hline \multicolumn{2}{c}{} & \multirow{2}{*}{ Direct effect } & \multicolumn{5}{c}{ Indirect effect } \\
\cline { 4 - 8 } & & & Total & $\rightarrow \mathrm{X}_{1}$ & $\rightarrow \mathrm{X}_{2}$ & $\rightarrow \mathrm{X}_{3}$ & $\rightarrow \mathrm{X}_{4}$ \\
\hline \multirow{3}{*}{ Low } & $\mathrm{X}_{1}$ & 0.074 & -0.0239 & & -0.0015 & -0.0676 & 0.0452 \\
& $\mathrm{X}_{2}$ & 0.061 & -0.0184 & -0.0018 & & -0.0232 & 0.0066 \\
& $\mathrm{X}_{3}$ & 0.227 & 0.0024 & -0.0221 & -0.0062 & & 0.0307 \\
& $\mathrm{X}_{4}$ & 0.234 & 0.0171 & -0.0143 & 0.0017 & 0.0297 & \\
\hline \multirow{4}{*}{ High } & $\mathrm{X}_{1}$ & 0.052 & -0.0517 & & 0.0004 & -0.0141 & -0.0380 \\
& $\mathrm{X}_{2}$ & -0.009 & 0.0405 & -0.0024 & & 0.0159 & 0.0270 \\
& $\mathrm{X}_{3}$ & 0.113 & 0.0491 & -0.0065 & -0.0013 & & 0.0569 \\
& $\mathrm{X}_{4}$ & 0.239 & 0.0176 & -0.0083 & -0.0010 & 0.0269 & \\
\hline
\end{tabular}

\section{Discussion}

Present study investigated the effect of climate and soil fertility on direct-seeded rice yield and growing period. There are many factors which could affect the rice growing period such as climate, variety and cultivation management. Early study revealed a significant influence of water stress on growing period for rainfed lowland rice (Inthavong et al., 2011). Present study showed that the growth period of direct-seeded rice in 2017 was longer 2 to 5 days than 2018, which may attribute to the lower average daily temperature in 2017. This result agreed with the study of Fulu et al. (2013) who demonstrated that the increase in temperature will lead to the advancement of rice phenology and the shortening of growth period. The difference in growth period between varieties was large and it might be related to the difference in rice genotypes. However, there was no remarkable difference between two soil fertilities in rice 
growing period and thus the growth period of direct-seeded rice might be mainly affected by climate condition and rice genotypes.

As far as yield formation was concerned, both soil fertility and meteorology had influences on direct-seeded rice yield in present study. The grain yield of GF-1, LY-168 and FLYX-1 in 2018 was significantly lower than 2017 and it could be explained by the decrement in seed-setting rate. Further reason might be related to the higher temperature of the flowering stage in 2017. Previous study already evidenced that heat stress could induce rice spikelet degeneration (Zhang et al., 2017). The study of Tang et al. (2018) also revealed that high temperature during the early grain filling stage could reduce rice yield by affecting the photosynthesis and antioxidant capacity. Furthermore, the study of Xuan et al. (2015) showed that average temperature at the flowering stage is higher than $30^{\circ} \mathrm{C}$ will reduce the rice seed setting rate. Moreover, we observed that the panicle number of $G F-1, L Y-168$ and $Q Y-801$ in 2018 was higher than 2017. It might relate to the higher sunshine hour in 2018 during the experiment. This result was consistent with the research of Liu et al. (2013) who demonstrated there was a correlation between sunshine hours and rice productivity. On the other hand, present study showed that soil fertility greatly affected the yield formation of direct-seeded rice. Soil fertility is an important indicator of soil fertility. It is a measure of the ability of soil to provide various nutrients needed for crop growth and it is also the comprehensive expression of various basic properties of soil, the most essential characteristic of soil which is different from parent material and other natural bodies, and the material basis of soil as natural resources and agricultural means of production (Rahman and Parkinson, 2007). Compared with low soil fertility, the grain yield of all rice varieties increased due to high soil fertility and the increment was attributed to the enhancement in grain number and panicle number. It indicated that the rice plant could develop more effective tillers under high fertility conditions. Our result was consistent with early study (Fan et al., 2016) which indicated that higher soil fertility could improve rice yield and its related trail. Our result also agreed with the investigation of Yadivinder et al. (2004) who indicated that there was a correlation between rice yield and soil fertility. Early study also evidenced the benefits of improved soil fertility on irrigated rice performance (Haefele et al., 2000). Furthermore, the study of Huang et al. (2010) showed that A. bisporus residues return could induce positive regulation in soil nutrients, soil enzymatic activities, $\mathrm{N}$ use efficiency and crop yields as organic manure in a paddy soil.

Combined with correlation analysis and path analysis, it can be found that the 1000grain weight is a factor which had the greatest impact on grain yield and is different from previous studies (Mirza et al., 1976) which showed that there was no significant correlation between grain yield and grain weight. The source of the difference was mainly caused by different varieties and cultivation management. Present study showed that soil fertility affected direct seeded rice yield by influencing the panicle number and grain number, however, the path analysis in this study divided two soil condition so that the difference in soil fertility was ignored. Therefore, the constituent factor that had the greatest impact on yield was not the panicle number and grain number. The effective panicle number under low fertility had a high negative impact on yield through the seed setting rate whilst the 1000-grain weight had a high positive impact on yield. Under high fertility, the number of effective panicles had a negative effect on the yield through seed setting rate and 1000-grain weight, which was related to the yield potential of rice. The light energy and the absorbed fertility are limited in the limited growth time of rice so the yield potential is limited (Du et al., 2018). Hence, the yield components are 
generally negatively correlated. However, the number of effective panicles per unit area under low fertility didn't reach the highest level in present study, and the yield potential was not fully realized, so the yield could be increased by other yield components. The seed-setting rate had a high positive impact on yield through 1000-grain weight, indicating that the rice has not reached the rice yield potential level in the late growth stage, and rice self-regulation by strengthening individual growth may attribute to insufficient fertility in the later stage (Ren et al., 2017).

\section{Conclusion}

Present study showed that the growing period of direct-seed rice was mainly affected by climate and genotypes. The soil fertility, meteorology and genotypes all had impact on yield formation of direct-seeded rice. The soil fertility influenced the grain yield by affecting the panicle number and grain number. was affected by Different soil fertility affected grain yield and related trail significantly. In addition, considered the highest yield was recorded in $Q Y-801$ in both years and both soil fertilities, Quanyou-801 might be the most suitable variety for direct-seeded rice planting in Central China. In order to revealed the mechanism of how meteorology and soil fertility affect the growth and development of rice, more study should be conducted at molecular and physiological level.

Acknowledgements. This study was supported by National Key Research and Development Program of China (2017YFD0301403). The authors declare no conflict of interests.

\section{REFERENCES}

[1] Chen, S., Xu, C., Yan, J., Zhang, X., Zhang, X., Wang, D. (2016): The influence of the type of crop residue on soil organic carbon fractions: An 11-year field study of rice-based cropping systems in southeast China. - Agriculture ecosystems \& Environment 223: 261269.

[2] Du, B., Luo, H. W., He, L. X., Zheng, A. X., Chen, Y. L., Zhang, T. T., Wang, Z. M., Hu, L., Tang, X. R. (2018): Deep fertilizer placement improves rice growth and yield in zero tillage. - Applied Ecology and Environmental Research 16: 8045-8054.

[3] Du, B., Luo, H. W., Liu, C., Lei, C. Y., Jiang, S. C., Lou, Y. G., Xu, Y. Y., Wang, M., Shi, L., Xing, D. Y. (2019): Effects of different water management methods on seeding rate, phenological and yielding properties of different rice cultivars (Oryza sativa L.). Applied Ecology and Environmental Research 17: 4269-4279.

[4] Fan, L. H., Shan-Shan, X. U., Hou, P. F., Xue, L. H., Gang-Hua, L. I., Ding, Y. F., Yang, L. Z. (2016): Effect of Different Ratios of Basal to Tiller Nitrogen on Rice Yield and Nitrogen Utilization Under Different Soil Fertility. - Scientia Agricultura Sinica.

[5] Fulu, T., Zhao, Z., Wenjiao, S., Yujie, L., Dengpan, X., Shuai, Z., Zhu, Z., Meng, W., Fengshan, L. (2013): Single rice growth period was prolonged by cultivars shifts, but yield was damaged by climate change during 1981-2009 in China, and late rice was just opposite. - Glob Chang Biol 19: 3200-3209.

[6] Haefele, S. M., Johnson, D. E., Diallo, S., Wopereis, M. C. S., Janin, I. (2000): Improved soil fertility and weed management is profitable for irrigated rice farmers in Sahelian West Africa. - Field Crops Research 66: 101-113.

[7] Hu, L., Du, P., Luo, H. W., Cheng, S. R., Wu, T. Y., He, J., Liu, Y. F., Meng, S. B., Chen, B. Y., Wang, Z. M., Tang, X. R. (2019): The effect of different cultivation methods 
on rice growth and development. - Applied Ecology and Environmental Research 17: 3867-3875.

[8] Huang, C., Deng, L., Gao, X., Zhang, S., Luo, T., Ren, Q. (2010): Effects of fungal residues return on soil enzymatic activities and fertility dynamics in a paddy soil under a rice-wheat rotation in Chengdu Plain. - Soil \& Tillage research 108: 16-23.

[9] Inthavong, T., Tsubo, M., Fukai, S. (2011): A water balance model for characterization of length of growing period and water stress development for rainfed lowland rice. - Field crops research 121: 291-301.

[10] Kong, L., Ashraf, U., Cheng, S., Rao, G., Mo, Z., Tian, H., Pan, S., Tang, X. (2017): Short-term water management at early filling stage improves early-season rice performance under high temperature stress in South China. - European journal of agronomy 90: 117-126.

[11] Liu, L., Zhu, Y., Tang, L., Cao, W., Wang, E. (2013): Impacts of climate changes, soil nutrients, variety types and management practices on rice yield in East China: A case study in the Taihu region. - Field crops research 149: 40-48.

[12] Mirza, M. J., Faiz, F. A., Mazid, A. (1976): Correlation studies and path analysis of plant height, yield and yield components in rice (Oryza sativa L.). - Nature 262: 17.

[13] Mo, Z. W., Pan, S. G., Ashraf, U., Kanu, A. S., Li, W., Wang, Z. M., Duan, M. Y., Tian, H., Kargbo, M. B., Tang, X. R. (2017): Local climate affects growth and grain productivity of precision hill-direct-seeded rice in South China. - Applied Ecology and Environmental Research 15: 113-125.

[14] Pan, S., Wen, X., Wang, Z., Ashraf, U., Tian, H., Duan, M., Mo, Z., Fan, P., Tang, X. (2017): Benefits of mechanized deep placement of nitrogen fertilizer in direct-seeded rice in South China. - Field Crops Research 203: 139-149.

[15] Rahman, S., Parkinson, R. J. (2007): Productivity and soil fertility relationships in rice production systems, Bangladesh. - Agricultural systems 92: 318-333.

[16] Rao, A. S., Alexander, D. (1988): Prediction of evapotranspiration and grain yield of rice (Oryza sativa L. cv Thriveni) in a humid tropical climate. - International Journal of Biometeorology 32: 81-86.

[17] Ren, Y., Ashraf, U., He, L. X., Mo, Z. W., Wang, F., Wan, X. C., Kong, H., Ran, X. L., Tang, X. R. (2017): Irrigation and nitrogen management practices affect grain yield and 2-ACETYL-1-PYRROLINE content in aromatic rice. - Applied Ecology and Environmental Research 15: 1447-1460.

[18] Seyfferth, A. L., McCurdy, S., Schaefer, M. V., Fendorf, S. (2014): Arsenic Concentrations in Paddy Soil and Rice and Health Implications for Major Rice-Growing Regions of Cambodia. - Environmental science \& technology 48: 4699-4706.

[19] Sun, B., Pan, X., Wang, D., Han, X., Zhang, Y., Hao, M., Chen, X. (2008): Effect of Nutrient Balance on Spatial and Temporal Change of Soil Fertility in Different Agriculture Area in China. - Advances in Earth Science 23: 1201-1208.

[20] Tang, S., Zhang, H., Li, L., Liu, X., Chen, L., Chen, W., Ding, Y. (2018): Exogenous spermidine enhances the photosynthetic and antioxidant capacity of rice under heat stress during early grain-filling period. - Functional plant biology 45: 911-921.

[21] Wang, Z., Gu, D., Beebout, S. S., Zhang, H., Liu, L., Yang, J., Zhang, J. (2018): Effect of irrigation regime on grain yield, water productivity, and methane emissions in dry directseeded rice grown in raised beds with wheat straw incorporation. - Crop journal 6: 495508.

[22] Xuan, S., Shi, C., Yang, L., Zhao, Y., Zhang, W., Cao, H., Xue, C. (2015): Prediction of the Natural Environmental High Temperature Influences on Mid-Season Rice Seed Setting Rate in the Middle-Lower Yangtze River Valley.

[23] Yadvinder-Singh, Bijay-Singh, Ladha, J. K., Khind, C. S., Gupta, R. K., Meelu, O. P., Pasuquin, E. (2004): Long-term effects, of organic inputs on yield and soil fertility in the rice-wheat rotation. - Soil Science Society of America Journal 68: 845-853. 
[24] Yonghua, T. Y. H. S. (2009): Distribution Characteristics of the Percentage of Soil Fertility Contribution and Its Associated Basic Crop Yield in Mainland China. - Journal of Agro-Environment Science 5: 1070-1078. (In Chinese).

[25] Zhang, C. X., Feng, B. H., Chen, T. T., Zhang, X. F., Tao, L. X., Fu, G. F. (2017): Sugars, antioxidant enzymes and IAA mediate salicylic acid to prevent rice spikelet degeneration caused by heat stress. - Plant growth regulation 83: 313-323.

[26] Zou, Y. B., Xia, B., Peng, J., Xie, X. B., Huang, M. (2015): Discussion on the Theory and Methods for Determining the Target Yield in Rice Production. - Scientia Agricultura Sinica.

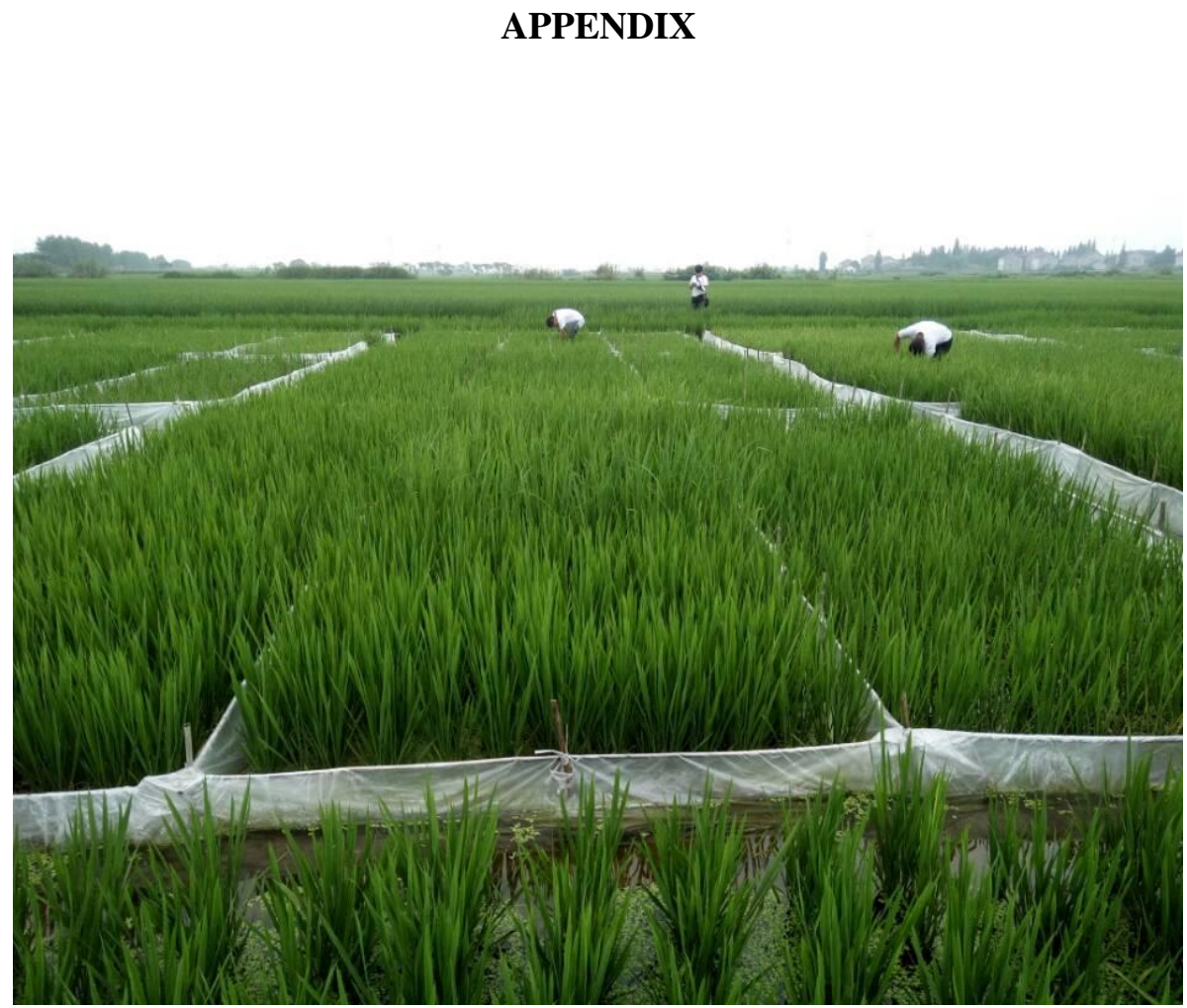

Appendix 1. Photo of the experiment 